\title{
Advances in the management of diabetes: new devices for type 1 diabetes
}

\author{
Wunna Wunna, ${ }^{1}$ Jovanna Tsoutsouki, ${ }^{1}$ Aisha Chowdhury, ${ }^{1}$ \\ Tahseen Ahmad Chowdhury (D) ${ }^{2}$
}

'Department of Diabetes, The Royal London Hospital, London, UK

${ }^{2}$ Diabetes and Metabolism, London, UK

\section{Correspondence to}

Tahseen Ahmad Chowdhury, The Royal London Hospital, 7th Floor, John Harrison House, Whitechapel, London E1 1BB, UK;

Tahseen.Chowdhury@nhs.net

Received 27 April 2020 Accepted 24 July 2020 Published Online First 20 August 2020

Check for updates

(c) Author(s) (or their employer(s)) 2021. No commercial re-use. See rights and permissions. Published by BMJ.

\begin{tabular}{l}
\hline To cite: Wunna W, \\
Tsoutsouki J, Chowdhury A, \\
et al. Postgrad Med J \\
2021;97:384-390. \\
\hline
\end{tabular}

\section{ABSTRACT}

Type 1 diabetes (T1D) is an autoimmune condition that affects a significant number of people worldwide, with higher prevalence in white European populations. The condition is responsible for a high burden of microvascular complications, especially when poorly controlled. The condition is also burdensome on the patient and has major psychosocial and occupational impacts. It requires lifelong frequent blood glucose monitoring and regular insulin injections. Important technological advances in the management of T1D have occurred in recent years. These include the advent of new glucose testing devices using interstitial glucose, and new insulin delivery devices. These technologies may improve quality of life, and glucose management in this condition. This review aims to outline the current advances in the management of T1D for the general physician, with a particular focus on new technologies.

\section{INTRODUCTION}

Type 1 diabetes (T1D) is a condition in which autoimmune pancreatic beta-cell destruction leads to absolute insulin deficiency. ${ }^{1}$ In 2017, it was estimated that 451 million people worldwide had diabetes, of whom around 10\% have T1D. ${ }^{2}$

As the condition often occurs in childhood or young adulthood, the potential for complications due to chronic hyperglycaemia is high, including blindness, end-stage kidney disease, cardiovascular complications and foot disease. ${ }^{3-9}$ Patients with T1D also have a higher risk of other autoimmune conditions, including vitiligo, coeliac disease, pernicious anaemia, thyroid disease and Addison's disease. ${ }^{1}$

Approximately $85 \%$ of cases of diabetes in people aged under 20 years is due to T1D. ${ }^{10}$ The disease is commoner among white European ethnic groups, especially in Northern Europe. ${ }^{11}$ Genetic factors appear important - the concordance rate for T1D in monozygotic twins is around $60 \%,{ }^{12}$ and while T1D usually occurs in people without a family history of diabetes, there is a 1 in 20 lifetime risk of developing T1D in individuals who have a first-degree relative with T1D (compared to 1 in 300 for the general population). ${ }^{13}$ Human leukocyte antigen (HLA) genes on chromosome 6 are shown to contribute around half of the genetic determination for T1D. ${ }^{14}$

There is also evidence of patterns in the seasonality of the diagnosis of T1D and the birth of individuals with T1D, with higher rates of T1D in children born in spring and lower rates in children born in autumn, ${ }^{15}$ and increased diagnosis in late autumn, winter and early spring. ${ }^{16}$ This has been suggested as evidence for an association with viral infections that might precipitate T1D. ${ }^{10}$ Viral respiratory tract infections in early life may lead to damage of beta-cells, autoimmunity and the development of T1D. ${ }^{17-19}$ This may be through molecular mimicry or bystander activation in genetically predisposed individuals. ${ }^{20}$ Systematic review suggests a strong link between enterovirus infection and T1D. ${ }^{21}$ Other viral aetiologies implicated include Epstein-Barr virus and cytomegalovirus. $^{22} 23$ Early exposure to cow's milk protein has been suggested as contributing to the aetiology of $\mathrm{T} 1 \mathrm{D},{ }^{24}$ although the data are not consistent. $^{25}$

\section{DIAGNOSIS OF T1D}

Most patients presenting with T1D will have osmotic symptoms and evidence of hyperglycaemia. At diagnosis, distinguishing between T1D and type 2 diabetes (T2D) is usually straightforward (table 1) but occasionally can be more difficult. ${ }^{26}$ Measurement of islet autoantibodies (glutamic acid decarboxylase, islet antigen 2, zinc transporter 8 ), may be helpful, as a significant positive titre suggests T1D. In addition, measurement of a non-fasting $\mathrm{C}$ peptide (with plasma glucose) may help, as the presence of high $\mathrm{C}$ peptide suggests a degree of pancreatic beta-cell function, which might suggest T2D. ${ }^{27}$ Distinguishing T1D from monogenic diabetes (also called maturityonset diabetes in the young) can also be challenging. Presence of a very strong family history and lack of ketosis might be a reasonable reason to consider genetic tests for monogenic diabetes. ${ }^{28}$

\section{GLYCAEMIC CONTROL IN T1D}

The Diabetes Control and Complications Trial (DCCT) and The Epidemiology of Diabetes Interventions and Complications (EDIC) studies explored whether complications of T1D could be

Table 1 Differences between type 1 and type 2 diabetes

\begin{tabular}{|c|c|}
\hline Type 1 diabetes & Type 2 diabetes \\
\hline Ketosis prone & Non-ketosis prone \\
\hline $\begin{array}{l}\text { Insulin deficient and absolute } \\
\text { requirement for insulin }\end{array}$ & $\begin{array}{l}\text { Variable degree of insulin } \\
\text { resistance with insulin deficiency }\end{array}$ \\
\hline Acute onset & Insidious onset \\
\hline Non-obese & Often obesity associated \\
\hline Usually younger onset & Usually older onset \\
\hline $\begin{array}{l}\text { Often islet autoantibody } \\
\text { positive (GAD) }\end{array}$ & Autoantibody negative \\
\hline
\end{tabular}


delayed. ${ }^{29}$ The DCCT study randomised 1441 people with T1D to intensive therapy (which aimed to get glycaemic levels as close as possible to the non-diabetic range) and conservative therapy (which aimed to keep participants asymptomatic). The EDIC study was an observational follow-up of the DCCT cohort. ${ }^{30}$

The DCCT study showed a $35-76 \%$ decrease in microvascular complications of T1D in the intensive therapy group. The median haemoglobin $\mathrm{A}_{1 \mathrm{c}}\left(\mathrm{HbA}_{1 \mathrm{c}}\right)$ in the intensive therapy group was $7 \%$ $(53 \mathrm{mmol} / \mathrm{mol})$ in comparison to $9 \%(75 \mathrm{mmol} / \mathrm{mol})$ in the conservative treatment group. During the course of the EDIC study, differences in $\mathrm{HbA}_{1 \mathrm{c}}$ disappeared between the two groups. Despite this, however, there was a durable effect on long-term complications in subjects in the intensive arm of the DCCT study. In both the DCCT and EDIC studies, intensive treatment resulted in longterm reductions in the risks of renal complications of diabetes, including microalbuminuria, macroalbuminuria, chronic kidney disease and cardiovascular disease. ${ }^{30-33}$ These studies also suggested that intensive glucose treatment in T1D delayed the onset and progression of diabetic retinopathy and peripheral neuropathy. ${ }^{31} 32$ Those in the intensive arm of the study also had long-term delays in the development and progression of cardiovascular disease and atherosclerosis, including a lower incidence of stroke, myocardial infarction and myocardial death. ${ }^{34}$

The main adverse effects of intensive treatment were hypoglycaemia and weight gain. Significantly more participants became overweight or obese in the intensive treatment arm. In addition, the frequency of severe hypoglycaemia was threefold higher in the intensive treatment group. There was no effect on quality of life (QoL) or cognitive function. ${ }^{35}$

\section{MANAGEMENT OF T1D}

Multiple-dose insulin therapy is the mainstay of treatment for people with T1D. ${ }^{35}$ The most physiological method of insulin administration is the basal-bolus regimen, which involves prandial subcutaneous rapid-acting insulin injections given just before meals, and one or two times per day long-acting basal insulin injections given usually before bed and/or on waking. In this regimen, around $50 \%$ of the total daily dose of insulin is given as basal, with the remaining $50 \%$ as given as rapid-acting insulin divided into mealtime doses, although the actual dose may vary according to prevailing glucose levels and carbohydrate intake.

A crucial aspect to treatment of T1D is the use of structured diabetes education. These education programmes include aspects regarding diet, blood glucose monitoring, dose adjustments depending on prevailing glucose levels and carbohydrate intake (carb counting), rules on the management of acute illness (sick day rules), driving and occupation, pregnancy and family planning, long-term complications of diabetes and the importance of regular follow-up and monitoring. One widely used education programme with good evidence for improved glycaemic control is the Dose Adjustment for Normal Eating (DAFNE) programme, ${ }^{36}$ which is recommended for all people with T1D within 6-12 months of diagnosis. ${ }^{37}$ The programme is usually led by specialist diabetes nurses and dietitians, and is a prime example of multidisciplinary working.

T1D is associated with a high burden of distress, ${ }^{38}$ and the assistance of psychologists and psychiatrists is often beneficial in managing these aspects, especially in patients with possible eating disorders or recurrent hyperglycaemic emergencies. ${ }^{39}$

Annual screening for microvascular and macrovascular complications is an important aspect in the management of people with T1D. All patients must have annual screening of the eyes (digital retinal screening), feet (for neuropathy and pulses) and kidneys (checking for elevated albumin creatinine ratio, or reducing estimated glomerular filtration rate). Timely management of early changes detected on screening can significantly reduce their progression.

In addition to this, the care should be individualised whenever it is possible-for example, giving appropriate support to patients with physical or mental disabilities, setting up individualised targets and care plans for different patients depending on their lifestyle and personal circumstances. Discussions with people with T1D should always be non-judgemental and aim to support improved QoL and control of glucose and other factors. Extra support is required for women with T1D aiming to achieve pregnancy even before conception, as outcomes can be significantly improved with better glucose control preconception. ${ }^{40}$

\section{NEW DEVICES FOR MANAGING T1D}

T1D is a lifelong condition associated with a poor QoL due to its high burden of care. Technological advances have the prospect of easing that burden for many patients.

\section{Glucose monitoring devices}

Self-monitoring of blood glucose (SMBG) is an integral part in the management of T1D. Since the development of the first glucometer in 1971, self-monitoring has been undertaken by obtaining finger-prick blood and using test strips inserted into a glucometer. In 1999, continuous glucose monitoring (CGM) devices were developed, which have been superior to the conventional SMBG devices in several ways. They provide frequent glucose monitoring, thus enabling more rapid treatment decisions. ${ }^{41}$ Their ability to alert the wearer to hypoglycaemia and hyperglycaemia leads to a reduction of acute diabetes-related complications. ${ }^{42}$ This combined with a reduction to the burden of capillary glucose testing leads to improvements in QoL. ${ }^{43}$

\section{How they work}

CGM measures interstitial fluid glucose levels, which, whilst reflecting prevailing blood glucose levels, show a delay of 10-15 min against blood glucose levels, which may be important particularly in the setting of hypoglycaemia. CGM devices comprise a sensor inserted beneath the skin, and a transmitter that transmits the data from the sensor to the receiver (meter, mobile phone application or insulin pump device). There are three different types: real-time CGM in which the blood glucose level can be checked at any time via the receiver, retrospective CGM in which the data can be downloaded for retrospective analysis and Flash CGM in which the individual patient has to scan the sensor to get a reading.

\section{Types of devices}

The first CGM was released by Medtronic in 1999. A measure of accuracy of CGM is the mean absolute relative difference (MARD) between the actual blood glucose and the CGM reading. The first Medtronic CGM had a MARD of $19.7 \%$, indicating that there could be a significant difference between the CGM reading and a prevailing actual blood glucose reading. In addition, users noted that there was some discomfort during the insertion and wearing of the device. Since then, however, the number of CGM devices has burgeoned, with much improved accuracy (MARD reduced to around $10 \%$ ) and comfort. ${ }^{44}$

The most widely used device currently in use is the flash glucose monitor, Freestyle Libre, developed in 2016 (figure 1). ${ }^{45}$ It requires scanning of the sensor in order to obtain a reading, but it does actually measure glucose readings continuously. The MARD is $10 \%$, and although there is currently no alarm system for 


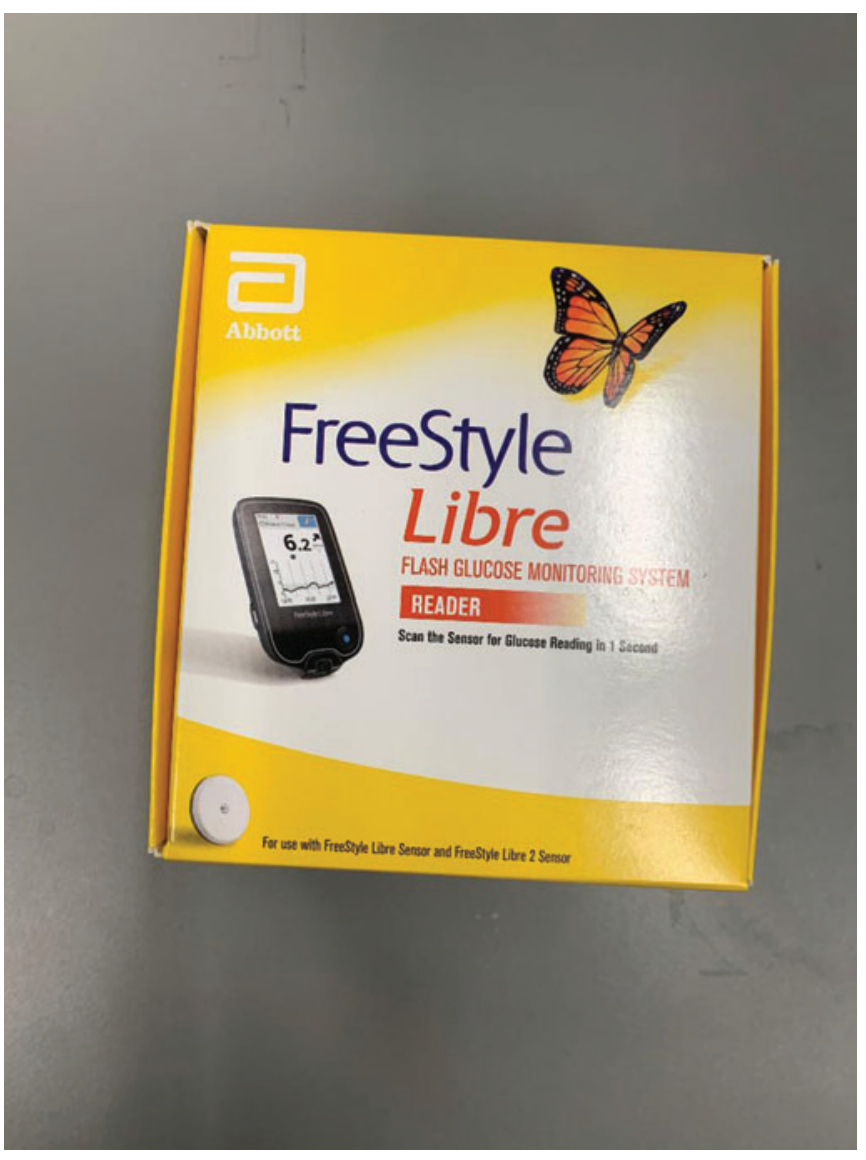

Figure 1 The Freestyle Libre flash glucose monitoring system.

low glucose levels, it is the most affordable system available, is water resistant and each sensor lasts for 14 days. A recent metaanalysis of studies of flash glucose monitoring suggests a mean of $0.4 \%$ reduction in $\mathrm{HbA} 1 \mathrm{c}$ in wearers compared to SMBG. ${ }^{46}$

Newer sensors, such as the Dexcom G6, can last for about 10 days and do not require calibration with blood glucose levels (figure 2). The Medtronic Guardian Sensor 3 was released in 2017 and integrated in the Medtronic MiniMed 670G insulin pump as a part of first hybrid insulin delivery and glucose monitoring system (see later). It requires calibration every 12 hours and has approximately 9.1\% MARD, and the sensor lasts for about 7 days. Medtronic Connect CGM was released in 2018. It uses Guardian Sensor 3 and can alert up to $60 \mathrm{~min}$ in advance of hypoglycaemic and hyperglycaemic events.

\section{Evidence}

Randomised controlled trials (RCTs) have shown that real-time CGM can improve glucose control as evidenced by $\mathrm{HbA}_{1 \mathrm{c}}$ reduction, without increasing the risk of hypoglycaemia. ${ }^{47}$ In the Multiple Daily Injections and Continuous Glucose Monitoring in Diabetes (DIAMOND) RCT, an improvement in diabetes-related QoL (distress related to hyperglycaemia, hypoglycaemic confidence) was seen. ${ }^{43}$ In the Sensing with insulin pump therapy to control $\mathrm{HbA}(1 \mathrm{c})(\mathrm{SWITCH})$ crossover study, CGM reduced $\mathrm{HbA}_{1 \mathrm{c}}$ and time spent in hypoglycaemia. ${ }^{48}$ Similarly, reduction of time spent in hypoglycaemia has been shown in a study which compared real-time flash glucose monitoring to traditional SMBG. ${ }^{42}$ There is also evidence that the use of CGM in pregnant women with T1D can improve glucose control and reduce adverse neonatal outcomes. $^{49}$

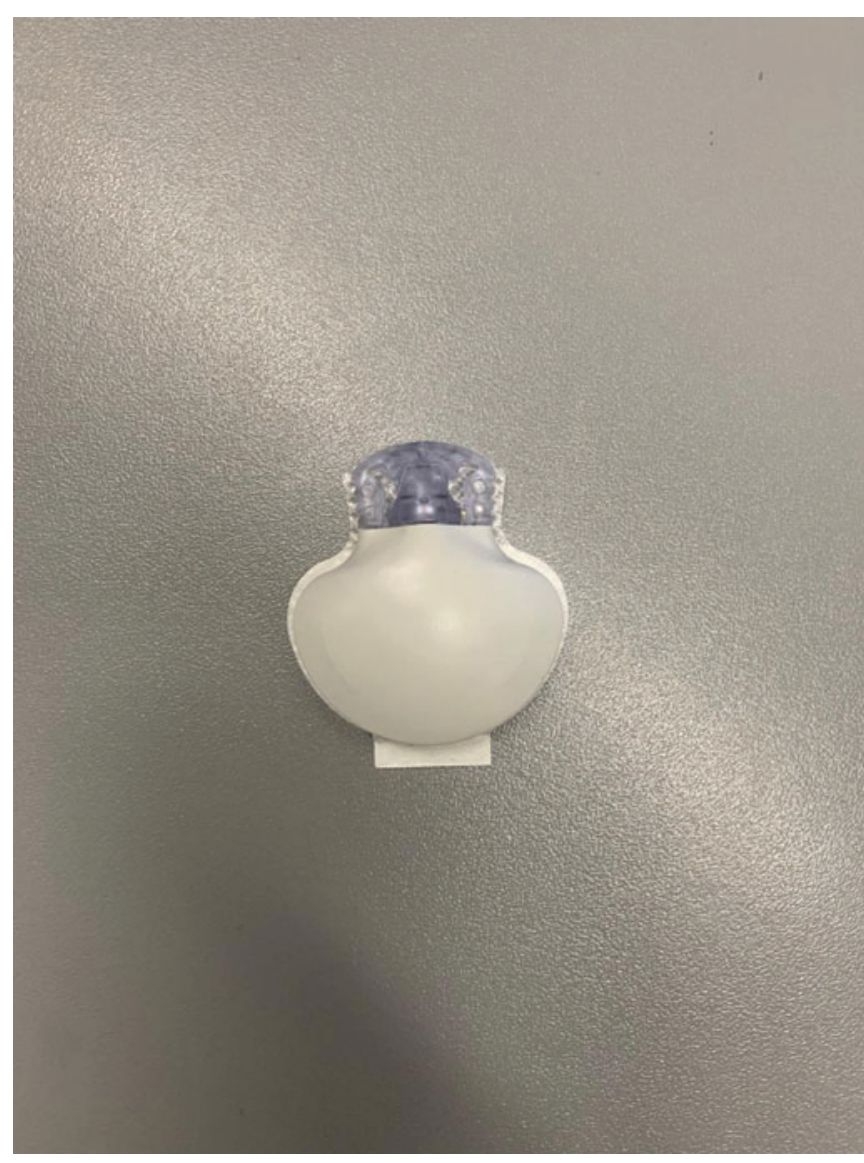

Figure 2 The Dexcom G6 continuous glucose monitoring sensor.

Use of CGM in patients with T2D is limited. One study has suggested a greater reduction in $\mathrm{HbA}_{1 \mathrm{c}}$ in patients with $\mathrm{T} 2 \mathrm{D}$ using CGM compared SMBG. ${ }^{50}$

\section{Eligibility in the UK}

According to National Institute for Health and Care Excellence (NICE) guidance, CGM can be offered to adults with T1D who are willing to use it at least $70 \%$ of the time and to calibrate it as necessary, and who have the following problems despite optimal use of multiple daily injections (MDI) and conventional SMBG: ${ }^{37}$

1. More than one episode a year of severe hypoglycaemia without any obvious precipitating cause.

2. Complete loss of awareness of hypoglycaemia

3. Frequent (more than two episodes) of asymptomatic hypoglycaemia that is causing problems with daily activities.

4. Extreme fear of hypoglycaemia.

5. Hyperglycaemia $\left(\mathrm{HbA}_{1 \mathrm{c}}\right.$ more than $\left.70 \mathrm{mmol} / \mathrm{mol}(9 \%)\right)$ despite SMBG testing more than 10 times a day.

The guidance also suggests continuing real-time CGM only if $\mathrm{HbA}_{1 \mathrm{c}}$ can be sustained at, or below $53 \mathrm{mmol} / \mathrm{mol}(7 \%)$ and/or there is a fall in $\mathrm{HbA}_{1 \mathrm{c}}$ of $27 \mathrm{mmol} / \mathrm{mol}(2.3 \%)$ or more.

\section{Continuous subcutaneous insulin infusion}

Continuous subcutaneous insulin infusion (CSII), also known as insulin pumps, was developed in 1963, and were worn as a large backpack. The first compact wearable pump was developed 10 years later, and insulin pump therapy began in earnest in the late 1970s. ${ }^{51}{ }^{52}$ Technology has improved such that it is now an important and effective treatment option in adults and children with T1D. 
The insulin pump contains an insulin reservoir which can store from 175 units to 300 units of rapid-acting insulin (such as insulin aspart (novorapid), insulin lispro (humalog)). There are three different forms of insulin pumps. In tethered pumps, the reservoir is attached to tubing with a needle or cannula at the other end to insert into the skin (eg, MiniMed 670G-figure 3). In patch pumps, the pump is directly attached to the skin and there is no risk of kinking or blocking of the tube (eg, Omnipod-figure 4). Finally, there is the implanted insulin pump, which is sited inside the body and delivers the insulin into the peritoneal cavity. This is rarely used currently, and refills of insulin currently can only be done in a hospital facility in Montpellier, France.

Insulin pumps deliver insulin as a 'basal rate' throughout the day, and specific rates of delivery can be set up for specific needs, depending on the activities of the individual. Some users prefer to have low basal rates at night-time in order to reduce the

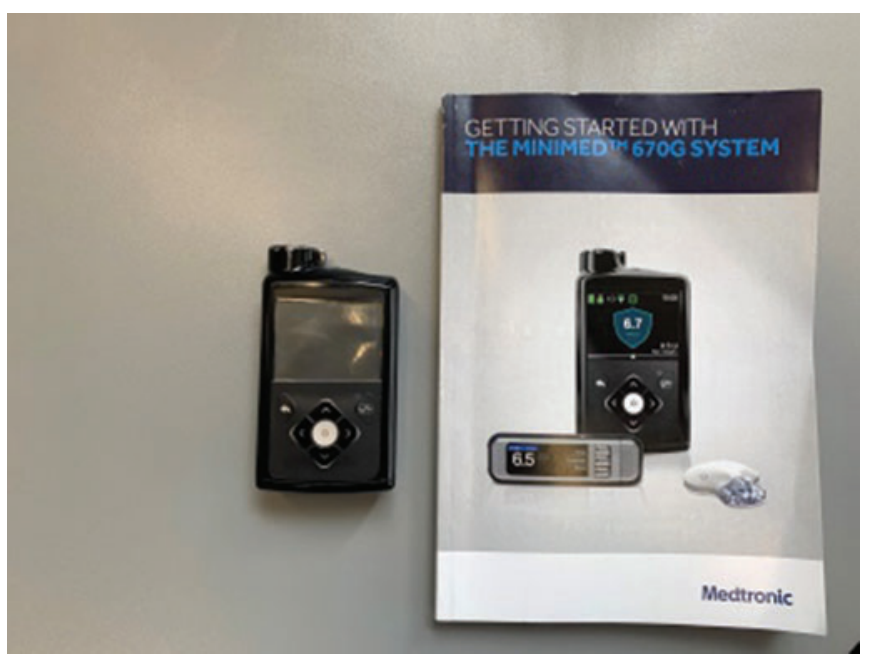

Figure 3 MiniMed 670G tethered pump.

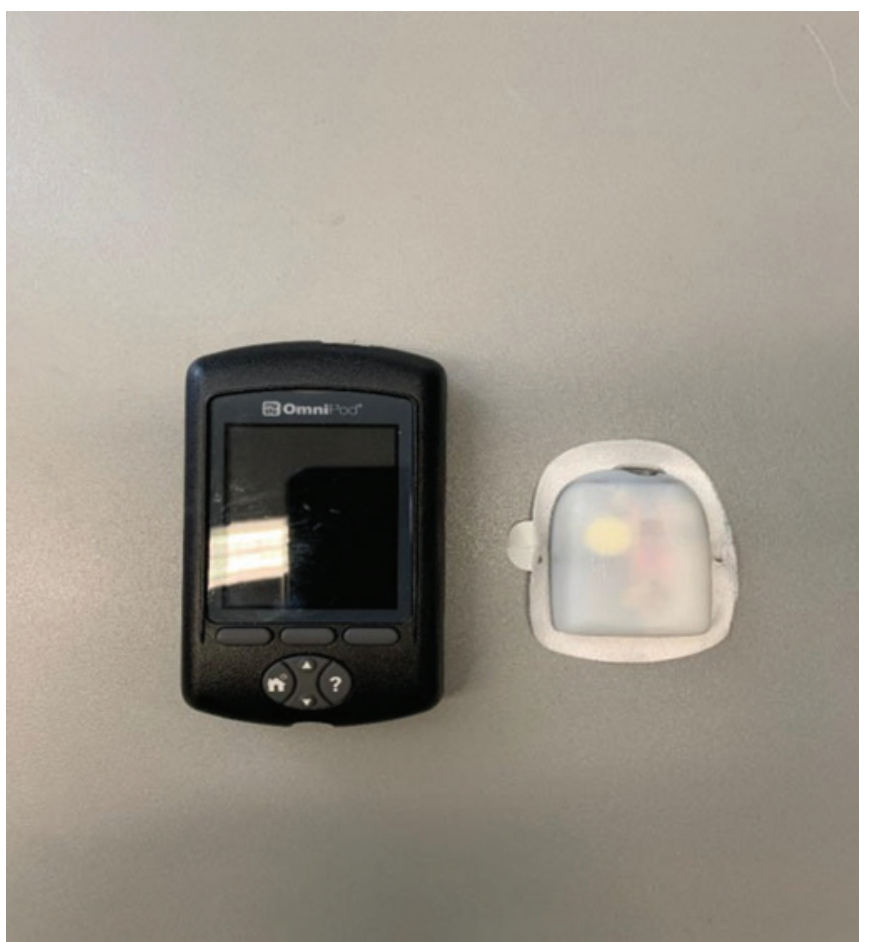

Figure 4 The Omnipod patch pump. risk of hypoglycaemia. Importantly, the user still needs to manually administer boluses of insulin at times when eating, by programming the pump to give an extra dose of insulin as per the individual's requirements.

\section{Types of insulin pumps}

There are a growing number of insulin pump devices and companies. Most pumps can directly link to CGM systems, and when linked with a CGM, are known as sensor-augmented pump therapy (SAPT). Some insulin pumps have an advanced feature that can switch off insulin delivery when blood glucose level is low (low glucose suspend), and indeed some pumps linked with CGM can predict the possibility of hypoglycaemia earlier and cut off the insulin delivery reducing the occurrence of hypoglycaemia significantly. ${ }^{53}$

\section{Evidence}

Many studies have been carried out to review the differences between insulin pump therapy and MDI, as well as between SAPT and MDI with SMBG. Meta-analysis of such studies suggests a reduction in severe hypoglycaemic episodes and $\mathrm{HbA}_{1 \mathrm{c}}$ with pump therapy. ${ }^{54}$ Studies in specific groups such as pregnant women with T1D, adults or children with T1D have also shown benefits even though in the case of pregnant women the benefits of SAPT are similar to those of MDI. ${ }^{55}$

SAPT is superior to MDI with SMBG without increasing the risk of hypoglycaemia. ${ }^{54}$ In terms of reduction in complications, RCTs in patients with T1D show that SAPT reduced albuminuria compared to MDI. ${ }^{56}$ A significant impact on QoL has also been noted in users of SAPT therapy, with major reduction in fear of hypoglycaemia and improvement in treatment satisfaction in adults. ${ }^{57}$

Not all studies, however, have shown improvements in outcomes with pump therapy. Restoration of hypoglycaemia awareness and prevention of severe hypoglycaemia without worsening overall metabolic control may be achieved with MDI as well. ${ }^{58}$ In addition, there has been no demonstrable difference in weight gain and number of diabetic ketoacidosis (DKA) episodes in SAPT compared to MDI. ${ }^{53-56}$ Some studies also suggest that there may be no difference in time spent in hyperglycaemia between insulin pump and MDI, although it may be shorter in patients on SAPT. ${ }^{54}$

While pump therapy is expensive, the cost-effectiveness of pump therapy has been demonstrated in certain patient groups. ${ }^{59}$

\section{Eligibility in the UK}

According to the current NICE guidance, insulin pump therapy is recommended for adults and children older than 12 years of age with T1D in the following circumstances ${ }^{60}$ :

1. Attempts to achieve the target $\mathrm{HbA}_{1 \mathrm{c}}$ level with MDI result in disabling hypoglycaemia (repeated and unpredictable hypoglycaemia resulting in persistent anxiety about recurrence and reducing the quality of life significantly).

2. Failure to achieve the target $\mathrm{HbA}_{1 \mathrm{c}}$ level $(8.5 \%$ or $69 \mathrm{mmol} /$ mol) on MDI therapy despite the high level of care.

3. CSII is also recommended in children of younger than 12 years of age with T1D if the MDI therapy is impractical or inappropriate and provided that they would be expected to undergo trial of MDI therapy between 12 years and 18 years of age.

\section{Hybrid insulin pump (closed-loop systems) and the artificial pancreas}

The advent of newer technology linking an insulin pump with CGM sensor and artificial intelligence technology, which can 
adjust the rate of delivery depending on the patient's prevailing glucose level detected by CGM, has been achieved. Proof-ofconcept studies have been published, and small studies of individuals living freely with such devices have also been undertaken. ${ }^{61}$

Medtronic released the first-ever hybrid insulin pump (closedloop system)-the MiniMed 670G with Guardian Sensor 3 in 2017, and it has been available in the UK from March 2019. In 'auto mode', this hybrid closed-loop insulin system adjusts the insulin basal rates every $5 \mathrm{~min}$ based on the glucose levels sensed by the CGM, in order to achieve the target blood glucose level. Early studies show that there is an improvement in $\mathrm{HbA}_{1 \mathrm{c}}$ and there is no occurrence of DKA or hypoglycaemia in initial safety trials. ${ }^{62}$ Eligibility is currently very limited in the UK.

More recently, studies of a bi-hormonal pump which releases insulin and glucagon, respectively, and can achieve nearnormoglycaemia, improved time in glucose range and reduction in hypoglycaemia. ${ }^{63}$

\section{CONCLUSIONS}

T1D carries a heavy personal burden and adversely affects quality and quantity of life. New technologies may have a considerable benefit in managing this burden. Ease of testing glucose has been a major goal of therapy for many years, and is finally fulfilling its potential. Delivery of insulin using CSII is a well-established therapy in many patients and has particular benefits for reducing hypoglycaemia and improving glucose control.

The management of T1D is, however, on the cusp of a major paradigm shift with the advent of closed-loop systems, which may have the benefit of managing glucose with lower burdens of care for the patient, and lower risk of adverse events. While the cost of these technologies is currently high, costs are likely to reduce as the technology becomes more easily available. The evidence for these technologies in reducing complications of T1D is, as yet, not available. If their efficacy can be demonstrated, then the costeffectiveness of these technologies is likely to be high, and their uptake is likely to grow.

\section{Main messages}

- Type 1 diabetes (T1D) is a lifelong condition, which is burdensome to manage and has adverse effects on quality and quantity of life.

- Standard management requires frequent injections of insulin and frequent blood glucose monitoring.

- Technological advances in testing of glucose can reduce the burden of testing for people with T1D. The Freestyle Libre device is now widely available and evidence of its benefit in the management of T1D is growing.

- Continuous subcutaneous insulin infusion (CSII) is a wellestablished treatment that can reduce the risk of hypoglycaemia and improve glucose control in people with T1D.

- Closed-loop systems linking continuous glucose monitoring with CSII have been developed and appear to improve glucose management and quality of life in people with T1D.

\section{Current research questions}

Do CGM, CSII or closed-loop systems reduce risk of microvascular and macrovascular complications and mortality in T1D?

- Can a closed-loop system manage T1D with minimal input from the patient?

\section{Key references}

1. American Diabetes Association. Diagnosis and classification of diabetes mellitus. Diabetes Care 2014;37(1):81-90.

2. DCCT Research Group. The effect of intensive treatment of diabetes on the development and progression of long-term complications in insulin-dependent diabetes mellitus. N Engl J Med 1993;329:977-986.

3. DAFNE Study Group. Training in flexible, intensive insulin management to enable dietary freedom in people with type 1 diabetes: dose adjustment for normal eating (DAFNE) randomised controlled trial. BMJ 2002;325(7367):746.

4. NICE Guideline NG17. Type 1 diabetes in adults: diagnosis and management. 2015. https://www.nice.org.uk/guidance/ng17 accessed 27 Apr 20

5. Benkhadra K, Alahdab F, Tamhane S, et al. Real-time continuous glucose monitoring in type 1 diabetes: a systematic review and individual patient data meta-analysis. Clin Endocrinol (Oxf) 2017;86(3):354-360.

\section{Self-assessment questions}

1. A 27-year-old woman was admitted with a first episode of diabetic ketoacidosis as a presenting feature of new-onset type diabetes. On recovery, she was commenced insulin therapy. Which of the following is the most appropriate insulin regimen?
a. Basal-bolus insulin.
b. Insulin pump therapy.
c. Once-daily basal insulin.
d. Three times a day 50/50 mixed insulin.
e. Two times per day 30/70 mixed insulin.

2. A 37-year-old woman with type 1 diabetes was admitted with hypoglycaemia. She noted that her awareness of hypoglycaemia had worsened recently. She was on a multipledose insulin regimen, and routine investigations were normal. She had appropriately reduced insulin doses, was carbohydrate counting and was rotating injection sites. Which of the following is the most appropriate course of action?

a. Change all insulins to alternative preparations.

b. Change of glucose metre.

c. Continuous subcutaneous insulin infusion (insulin pump).

d. Hybrid closed-loop system.

e. Reduction in insulin doses by $50 \%$.

3. A 25-year-old man with type 1 diabetes was keen to undertake flash glucose monitoring using a Freestyle Libre. Which of the following statement(s) concerning flash glucose monitoring are correct?

a. It alarms if the glucose goes below $3 \mathrm{mmol} / \mathrm{L}$.

b. The glucose sensor needs to be changed daily.

c. The sensors can never be used in water.

d. There is good evidence for improvement in quality of life.

e. There is good evidence of reduction in microvascular disease.

4. A 24-year-old woman with type 1 diabetes was keen on managing her diabetes with a closed-loop system. Which of the following is currently correct?

a. Closed-looposed loop systems are likely to be widely available in the next one year.

b. Closed-loop systems can be used with a Freestyle Libre. 
c. Closed-loop systems do not require the patient to do any self-monitoring.

d. Closed-loop systems have proven cost-effectiveness.

e. Closed-loop systems may involve use of insulin and glucagon pumps.

5. A 23-year-old man with type 1 diabetes developed problems with hypoglycaemia and was keen to undertake some form of continuous glucose monitoring (CGM). Which of the following statement(s) concerning CGM are correct?

a. CGM can only be used in conjunction with an insulin pump.

b. CGM is available for all people with T1D.

c. CGM is cheaper than flash glucose monitoring (Freestyle Libre).

d. CGM is proven to reduce microvascular complications of diabetes.

e. Glucose readings from the CGM can be used to assess ability to drive.

Twitter wunna_wn.

Contributors WW wrote the main sections on the management of T1D and devices. AC and JT contributed sections, referenced, reviewed and revised the manuscript. TAC conceived the idea, wrote and rewrote various sections including the self-assessment questions. TAC is the guarantor.

Funding None.

Competing interests None declared.

Patient consent for publication Not required.

Provenance and peer review Not commissioned; internally peer reviewed.

ORCID iD

Tahseen Ahmad Chowdhury http://orcid.org/0000-0001-8878-2331

\section{REFERENCES}

1 American Diabetes Association. Diagnosis and classification of diabetes mellitus. Diabetes Care 2014;37:81-90.

2 Cho NH, Shaw JE, Karuranga S, et al. IDF diabetes atlas: global estimates of diabetes prevalence for 2017 and projections for 2045. Diabetes Res Clin Pract 2018;138:271-81.

3 Zheng Y, Ley S, Hu F. Global aetiology and epidemiology of type 2 diabetes mellitus and its complications. Nat Rev Endocrinol 2018;14:88-98.

4 Tatti P, Di Mauro P, Masselli L, et al. Prevention of diabetic eye disease: the commonest cause of blindness in individuals younger than 65 years. Clin Ophthalmol 2010:4:1291-8.

5 Tuttle KR, Bakris GL, Bilous RW, et al. Diabetic kidney disease: a report from an ADA consensus conference. Diabetes Care 2014;37:2864-83.

6 Tun NN, Arunagirinathan G, Munshi SK, et al. Diabetes mellitus and stroke: a clinical update. World J Diabetes 2017:8:235-48.

7 Li X, Jiao Y, Xing Y, et al. Diabetes mellitus and risk of hepatic fibrosis/cirrhosis. Biomed Res Int 2019:2019:5308308.

8 Starup-Linde J, Karlstad O, Eriksen SA, et al. CARING (CAncer Risk and INsulin analoGues): the association of diabetes mellitus and cancer risk with focus on possible determinants - a systematic review and a meta-analysis. Curr Drug Saf 2013;8:296-332.

9 Bell DS. Heart failure: a serious and common comorbidity of diabetes. Clin Diab 2004;22:61-5.

10 Maahs DM, West NA, Lawrence JM, et al. Epidemiology of type 1 diabetes. Endocrinol Metab Clin N Am 2010;39:481-97.

11 Dabelea D, Bell RA, D'Agostino RB JrWriting Group for the SEARCH for Diabetes in Youth Study Group. et al. Incidence of diabetes in youth in the United States. JAMA 2007;297:2716-24

12 Redondo MJ, Jeffrey J, Fain PR, et al. Concordance for islet autoimmunity among monozygotic twins. N Engl J Med 2008;359:2849-50.

13 Redondo MJ, Fain PR, Eisenbarth GS. Genetics of type 1A diabetes. Recent Prog Horm Res 2001;56:69-89.

14 Mehers KL, Gillespie KM. The genetic basis for type 1 diabetes. Br Med Bull 2008:88:115-29.

15 Kahn HS, Morgan TM, Case LD, et al. Association of type 1 diabetes with month of birth among U.S. youth: the search for diabetes in youth study. Diabetes Care 2009:2010-5.

16 Ostman J, Lonnberg G, Arnqvist HJ, et al. Gender differences and temporal variation in the incidence of type 1 diabetes: results of 8012 cases in the nationwide diabetes incidence study in Sweden 1983-2002. J Intern Med 2008;263:386-94.
17 Rasmussen T, Witsø E, Tapia G, et al. Self-reported lower respiratory tract infections and development of islet autoimmunity in children with the type 1 diabetes high-risk HLA genotype: the MIDIA study. Diabetes Metab Res Rev 2011:27:834-7.

18 Beyerlein A, Wehweck F, Ziegler AG, et al. Respiratory infections in early life and the development of islet autoimmunity in children at increased type 1 diabetes risk: evidence from the BABYDIET study. JAMA Pediatr 2013;167:800-7.

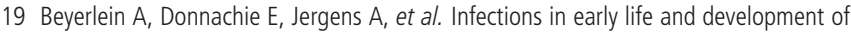
type 1 diabetes. JAMA 2016:1899-901.

20 Prinicipi N, Berioli MG, Bianchini S, et al. Type 1 diabetes and viral infections: what is the relationship? J Clin Virol 2017:96:26-31.

21 Yeung WC, Rawlinson WD, Craig ME. Enterovirus infection and type 1 diabetes mellitus: systematic review and meta-analysis of observational molecular studies. BMJ 2011;342:35.

22 Bian X, Wallstrom G, Davis A, et al. Immunoproteomic profiling of antiviral antibodies in new-onset type 1 diabetes using protein arrays. Diabetes 2016;65:285-96.

23 Osame K, Takahashi Y, Takasawa H, et al. Rapid-onset type 1 diabetes associated with cytomegalovirus infection and islet autoantibody synthesis. Intern Med 2007;46:8737.

24 Gerstein HC. Cow's milk exposure and type I diabetes mellitus. A critical overview of the clinical literature. Diabetes Care 1994;17:13-19.

25 Norris JM, Scott FW. A meta-analysis of infant diet and insulin-dependent diabetes mellitus: do biases play a role? Epidemiology 1996;7:87-92

26 Misra S, Oliver N, Dornhorst A. Diabetic ketoacidosis: not always due to type 1 diabetes. BMJ 2013;346:3501

27 Thomas NJ, Lynam AL, Hill AV, et al. Type 1 diabetes defined by severe insulin deficiency occurs after 30 years of age and is commonly treated as type 2 diabetes. Diabetologia 2019;62:1167-72.

28 Hattersley AT, Patel KA. Precision diabetes: learning from monogenic diabetes. Diabetologia 2017:60:769-77. .

29 DCCT Research Group. The effect of intensive treatment of diabetes on the development and progression of long-term complications in insulin-dependent diabetes mellitus. N Engl J Med 1993:329:977-86.

30 de Boer IHDCCT/EDIC Research Group. Kidney disease and related findings in the diabetes control and complications trial/epidemiology of diabetes interventions and complications study. Diabetes Care 2014;37:24-30.

31 Aiello LPDCCT/EDIC Research Group. Diabetic retinopathy and other ocular findings in the diabetes control and complications trial/epidemiology of diabetes interventions and complications study. Diabetes Care 2014;37:17-23.

32 Martin CL, Albers JW, Pop-Busui RDCCT/EDIC Research Group. Neuropathy and related findings in the diabetes control and complications trial/epidemiology of diabetes interventions and complications study. Diabetes Care 2014:37:31-8.

33 Lachin JM, Orchard TJ, Nathan DMDCCT/EDIC Research Group. Update on cardiovascular outcomes at 30 years of the diabetes control and complications trial/epidemiology of diabetes interventions and complications study. Diabetes Care 2014;37:39-43.

34 Jacobson AM, Musen G, Ryan C, et al.DCCT/EDIC Research Group. Long-term effect of diabetes and its treatment on cognitive function. N Engl J Med 2007; 356: $1842-52$.

35 Bolli GB. Physiological insulin replacement in type 1 diabetes mellitus. Exp Clin Endocrinol Diabetes 2001;109:S317-32.

36 DAFNE Study Group. Training in flexible, intensive insulin management to enable dietary freedom in people with type 1 diabetes: dose adjustment for normal eating (DAFNE) randomised controlled trial. BMJ 2002;325:746.

37 NICE Guideline NG17. Type 1 diabetes in adults: diagnosis and management. 2015. Available https://www.nice.org.uk/guidance/ng17 (accessed 27 Apr 2020)

38 Hagger V, Hendrieckx C, Sturt J, et al. Diabetes distress among adolescents with type diabetes: a systematic review. Curr Diab Rep 2016:16:9.

39 Garrett C, Doherty A. Diabetes and mental health. Clin Med (Lond) 2014;201:669-72

40 Rosenn B, Miodovnik M, Combs CA, et al. Pre-conception management of insulin-dependent diabetes: improvement of pregnancy outcome. Obstet Gynecol 1991;77:846-9.

41 Benkhadra K, Alahdab F, Tamhane S, et al. Real-time continuous glucose monitoring in type 1 diabetes: a systematic review and individual patient data meta-analysis. Clin Endocrinol (Oxf) 2017:86:354-60.

42 Bolinder J, Antuna R, Geelhoed-Duijvestijn P, et al. Novel glucose-sensing technology and hypoglycaemia in type 1 diabetes: a multicentre, non-masked, randomised controlled trial. Lancet 2016;388:2254-63.

43 Beck RW, Riddlesworth T, Ruedy K, et al. Effect of continuous glucose monitoring on glycemic control in adults with type 1 diabetes using insulin injections: the DIAMOND randomized clinical trial. JAMA 2017;317:371-8.

44 Gifford R. Continuous glucose monitoring: 40 years, what we've learned and what's next. Chemphyschem 2013;14:2032-44.

45 Leelarathna L, Wilmot EG, Flash forward: a review of flash glucose monitoring. Diabet Med 2018;35:472-82.

46 Gordon I, Rutherford C, Makarounas-Kirchmann K, et al. Meta-analysis of average change in laboratory-measured $\mathrm{HbA} 1 \mathrm{c}$ among people with type 1 diabetes mellitus using the 14 day flash glucose monitoring system. Diabetes Res Clin Pract 2020;164:108158 
47 Juvenile Diabetes Research Foundation Continuous Glucose Monitoring Study Group. Effectiveness of continuous glucose monitoring in a clinical care environment: evidence from the Juvenile Diabetes Research Foundation Continuous Glucose Monitoring (JDRF-CGM) trial. Diabetes Care 2010;33:17-22.

48 Battelino T, Conget I, Olsen B, et al. The use and efficacy of continuous glucose monitoring in type 1 diabetes treated with insulin pump therapy: a randomised controlled trial. Diabetologia 2012;55:3155-62.

49 Feig DS, Donovan LE, Corcoy R, et al. Continuous glucose monitoring in pregnant women with type 1 diabetes (CONCEPTT): a multicentre international randomised controlled trial. Lancet 2017;390:2347-59.

50 Taylor PJ, Thompson CH, Brinkworth GD. Effectiveness and acceptability of continuous glucose monitoring for type 2 diabetes management: a narrative review. I Diabetes Investig 2018:9:713-25.

51 Tamborlane WV, Sherwin RS, Genel M, et al. Reduction to normal of plasma glucose in juvenile diabetes by subcutaneous administration of insulin with a portable infusion pump. N Engl J Med 1979;300:573-8.

52 Pickup JC, Keen H, Parsons JA, et al. Continuous subcutaneous insulin infusion: an approach to achieving normoglycaemia. Br Med J 1978;1:204-7.

53 Garg SK, Weinzimer SA, Tamborlane WV, et al. Glucose outcomes with the in-home use of a hybrid closed-loop insulin delivery system in adolescents and adults with type 1 diabetes. Diabetes Technol Ther 2017;19:155-63.

54 Yeh HC, Brown TT, Maruthur N, et al. Comparative effectiveness and safety of methods of insulin delivery and glucose monitoring for diabetes mellitus: a systematic review and meta-analysis. Ann Intern Med 2012;157:336-47.

55 Ranasinghe PD, Maruthur NM, Nicholson WK, et al. Comparative effectiveness of continuous subcutaneous insulin infusion using insulin analogs and multiple daily injections in pregnant women with diabetes mellitus: a systematic review and meta-analysis. J Womens Health (Larchmt) 2015;24:237-49.

56 Rosenlund S, Hansen TW, Rossing P, et al. Effect of sensor-augmented pump treatment versus multiple daily injections on albuminuria: a 1-year randomized study. J Clin Endocrinol Metab 2015;100:4181-8.

57 Rubin RR, Peyrot MSTAR 3 Study Group. Health-related quality of life and treatment satisfaction in the sensor-augmented pump therapy for A1C reduction 3 (STAR 3) trial. Diabetes Technol Ther 2012 Feb; 14:143-15.

58 Little SA, Leelarathna L, Walkinshaw E, et al. Recovery of hypoglycemia awareness in long-standing type 1 diabetes: a multicenter $2 \times 2$ factorial randomized controlled trial comparing insulin pump with multiple daily injections and continuous with conventional glucose self-monitoring (HypoCOMPaSS). Diabetes Care 2014;37:2114-22

59 Roze S, de Portu S, Smith-Palmer J, et al. Cost-effectiveness of sensor-augmented pump therapy versus standard insulin pump therapy in patients with type 1 diabetes in Denmark. Diabetes Res Clin Pract 2017;128:6-14.

60 NICE. Continuous subcutaneous insulin infusion for the treatment of diabetes mellitus. Technology appraisal guidance [TA151]. [internet] Available https://www.nice.org.uk/ guidance/TA151/chapter/1-guidance (accessed 27 Apr 2020)

61 Weaver KW, Hirsch IB. The hybrid closed-loop system: evolution and practical applications. Diabetes Technol Ther 2018;20:216-23.

62 Anderson SM, Buckingham BA, Breton MD, et al. Hybrid closed-loop control is safe and effective for people with type 1 diabetes who are at moderate to high risk for hypoglycemia. Diabetes Technol Ther 2019;21:356-63.

63 Russell SJ, El-Khatib FH, Sinha M, et al. Outpatient glycemic control with a bionic pancreas in type 1 diabetes. N Engl J Med 2014;37:313-25. 